(C) 2017 IEEE. Personal use of this material is permitted. Permission from IEEE must be obtained for all other uses, in any current or future media, including reprinting/republishing this material for advertising or promotional purposes, creating new collective works, for resale or redistribution to servers or lists, or reuse of any copyrighted component of this work in other works. 


\title{
Space Vector Modulation based Proportional Resonant Current Controller with Selective Harmonics Compensation for Matrix Converter Systems
}

\author{
Jianwei Zhang ${ }^{1}$, $\mathrm{Li} \mathrm{Li}^{1}$, David G. Dorrell ${ }^{2}$, and Youguang Guo ${ }^{1}$ \\ ${ }^{1}$ Faculty of Engineering and IT, University of Technology Sydney, Sydney, Australia \\ ${ }^{2}$ University of KwaZulu-Natal, Howard College Campus, Durban, South Africa \\ Email: Jianwei.Zhang@uts.edu.au, Li.Li@uts.edu.au,dorrelld@ukzn.ac.za and Youguang.Guo-1@uts.edu.au
}

\begin{abstract}
The matrix converter has emerged as a direct AC/AC converter and has attracted research attention. This work proposes a Proportional Resonant (PR) controller based on the Space Vector Modulation (SVM) method for the three-phase direct matrix converter and its application systems. The PR controller, compared with the widely used PI controller, has better steady-state error performance, specific harmonics compensation capability, and the ability to handle sinusoidal quantities. These enhance the tracking performance of the converters and benefit the current quality improvement and selective harmonics suppression. The PR controller can be implemented in the natural frame in a straightforward manner, which removes the frame transformations involved in the stationary $(\alpha \beta)$ and synchronous $(d q)$ reference frame based control strategies. This alleviates the computation burden. Simulation results verify the effectiveness of the proposed PR controller for the matrix converter applications.
\end{abstract}

Index Terms-Matrix Converter, Space Vector Modulation, Proportional Resonant Controller, Harmonics Compensation

\section{INTRODUCTION}

The three-phase direct matrix converter (shown in Fig. 1) is a direct $\mathrm{AC}$ to $\mathrm{AC}$ converter and has attracted attention due to features such as direct conversion, bidirectional power flow, sinusoidal waveforms, controllable input power factor, and compact volume [1], [2]. It can be utilized in a wide range of applications. Current regulation of the matrix converter is an important issue. Numerous control methods have been proposed for the matrix converter. Among them, space vector modulation (SVM) has been widely used either in open loop mode or in closed loop mode with sliding mode controllers [3], [4] or PI controllers [5], as well as other forms of controller. In closed loop control, control strategies can be generally classified into natural frame $(a b c)$, stationary frame $(\alpha \beta)$ and synchronous reference frame $(d q)$ approaches. Both $\alpha \beta$ and $d q$ based control methods require multiple frame transformations leading to the increased computation burden.

PI controllers are simple, easy to implement and have become an industry standard controller. They have been widely employed in converter control and other industrial applications [6]. In terms of the matrix converter, PI controllers based on the SVM have been investigated in [1] as a power flow controller for transmission systems. However, PI controllers have the known drawback of

This work is supported in part by the China Scholarship Council (File No. 201406300161) failing to remove the steady-state error when regulating sinusoidal quantities. PI controllers are only suitable for the synchronous reference frame based control to track DC constants as it provides an infinite gain only at zero frequency [7]. This also explains the inability of PI controllers to track sinusoidal variables (poor steady-state error performance). Moreover, PI controllers require complex frame transformations for the three-phase system control applications. In addition, the decoupling issue in the PI controller with the synchronous reference frame has to be tackled. Extensive efforts have been made to solving these problems; however some of the methods may push the system to its stability limits [8].

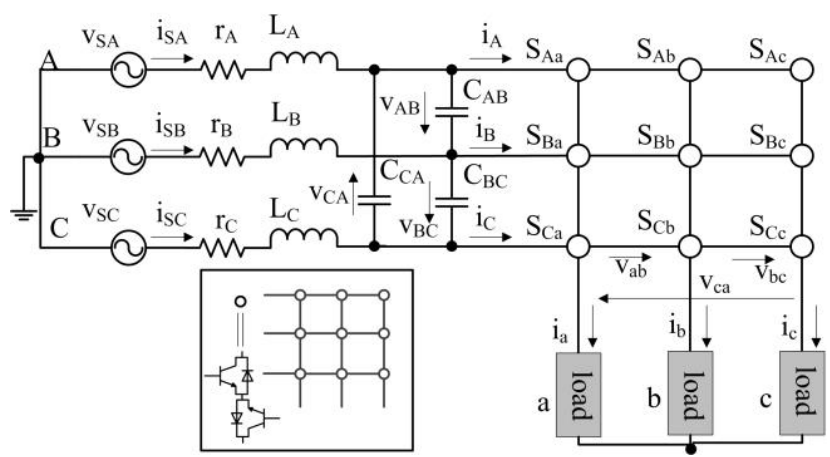

Fig. 1. Three-phase direct matrix converter system.

These problems can be handled by the proportional resonant (PR) controller which offers excellent steadystate error performance and provides specific-order harmonic compensation with affordable computational burden [9], [10]. Resonant controllers have been proved to be a good alternative to PI controllers in the current loop control. With the penetration of renewable energy systems into the grid, some standards and codes impose more stringent requirement on the current quality and harmonic content. PI controllers are not able to deal with low-order harmonics efficiently. Otherwise high proportional gain is required which pushes the stability of the system to a critical level [11]. In contrast, PR controllers are efficient in terms of compensating for selective current harmonics. For grid-interface and synchronization applications, grid frequency fluctuation is an issue that should be considered when designing controllers. This issue can be tackled with the inclusion of grid frequency information in the PR controller, which makes it frequency adaptive and more robust. The PR 
controller has been proposed for some converters and good performance has been reported [12]-[15].

PR controllers have not been applied in a matrix converter. This work proposes a PR controller for the matrix converter and this scheme can be applied in relevant applications such as grid synchronization and distributed renewable energy generation. SVM, as described in Section III, is used to form the closed current loop. The controller is simple and implemented in the natural $a b c$ frame, therefore complex frame transformations are avoided. Selective current harmonics can be regulated effectively. The simulation results in Section V verify the effectiveness of the PR controller controlling the matrix converter.

\section{PR CONTROLLER DESIGN}

The design of the PR controller is straightforward. Briefly, the PR controller provides an infinite gain at the targeted frequencies to eliminate the steady-state error at these frequencies and to provide harmonic compensation by cascading multiple PR controllers.

\section{A. PR Controller}

The derivation of an ideal PR controller can be achieved by transforming a synchronous reference frame based PI controller into a stationary frame based controller. The ideal PR controller:

$$
G_{P R}(s)=K_{P}+\frac{2 K_{R} s}{s^{2}+\omega^{2}}
$$

provides an infinite gain at the $\mathrm{AC}$ frequency $\omega$ and causes no phase shift at other frequencies. $K_{P}$ and $K_{R}$ are the proportional and resonant gains respectively; $\omega_{c}<<\omega$ is the cut-off frequency, which affects the bandwidth around the resonance frequencies.

However, the implementation of an ideal PR controller is not practical due to the infinite quality factor [6]. Therefore, an approximated PR controller is usually adopted:

$$
G_{P R}(s)=K_{P}+\frac{2 K_{R} \omega_{c} s}{s^{2}+2 \omega_{c} s+\omega^{2}}
$$

The approximated PR controller has wider bandwidth around the targeted frequencies, which leads to less sensitivity, thus more robustness to frequency variations around these targeted frequencies as shown in Fig. 5.

\section{B. PR Controller with Harmonics Compensator}

By cascading several PR controllers with different resonant frequencies, the ideal PR controller becomes

$$
G_{P R}(s)=K_{P}+\sum_{n=1,3,5,7} \frac{2 K_{R n} s}{s^{2}+(n \omega)^{2}}
$$

and the approximated PR controller is

$$
G_{P R}(s)=K_{P}+\sum_{n=1,3,5,7} \frac{2 K_{R n} \omega_{c} s}{s^{2}+2 \omega_{c} s+(n \omega)^{2}}
$$

where $n$ is the harmonic order and $K_{R n}$ represents the individual resonant gain for the $n^{\text {th }}$ harmonic. Thus the ideal and approximated selective harmonic compensators (3) and (4) are obtained as shown in Figs. 2 and 4 respectively. Their amplitude and frequency responses (Bode diagrams) are shown in Figs. 3 and 5 respectively. It is worth noting that gains at resonant frequencies can be tuned. Here, for simplicity, $K_{P}=K_{R n}=1$ is used.

For the harmonic compensator, the targeted frequencies can be designed according to specific applications. However, the $3^{\text {rd }}, 5^{\text {th }}$ and $7^{\text {th }}$ order harmonics are usually considered as they are regarded as the most prominent harmonics in a typical current spectrum [16].

From Figs. 3 and 5, it is observed that the PR controller and harmonic compensator provide great gains only at the targeted frequencies and they do not introduce a phase shift to other frequencies. Compared with the ideal PR controller, the approximated PR controller has a wider bandwidth around the targeted frequencies, which results in better robustness to frequency variations.

The output current errors of a matrix converter pass through the PR controllers (with harmonic compensators) to provide the voltage references. These references are then delivered to the SVM (Section III) to generate the gating pulses for the matrix converter. The matrix converter input currents are also controlled with this scheme and the input power factor can be regulated to unity. Controller parameters should be tuned appropriately to obtain the desired results, which may be carried out in the same way as in a PI controller.

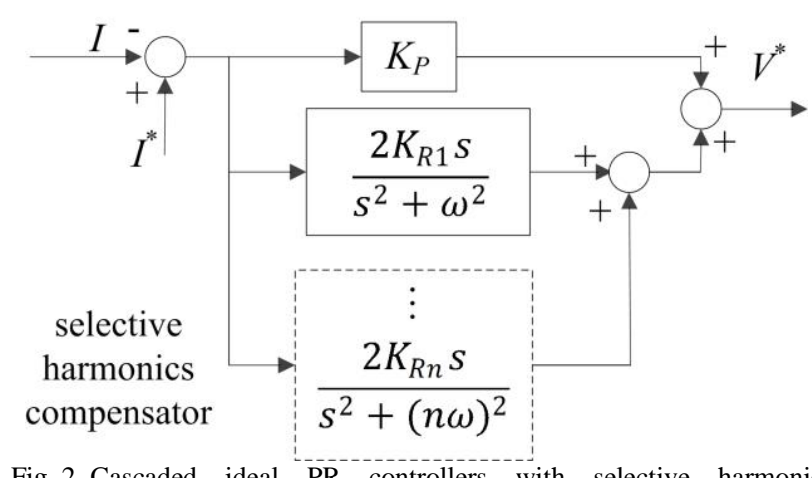

Fig. 2. Cascaded ideal $\mathrm{PR}$ controllers with selective harmonic compensation.

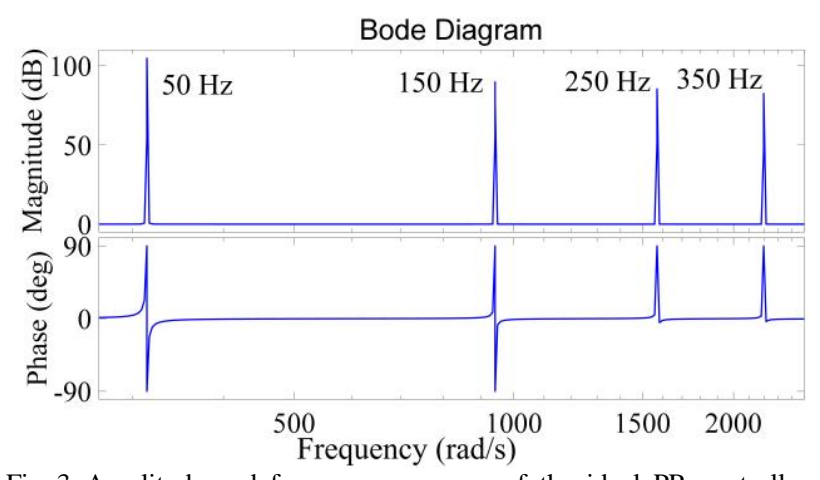

Fig. 3. Amplitude and frequency response of the ideal PR controllers with selective harmonics compensator $\left(K_{P}=1, K_{R n}=1, \omega=100 \pi \mathrm{rad} / \mathrm{s}\right)$. 


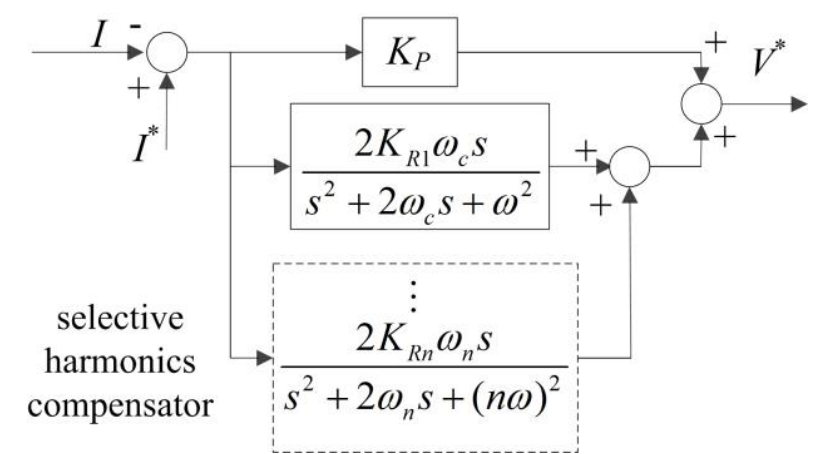

Fig. 4. Cascaded approximated PR controllers with harmonic compensation.

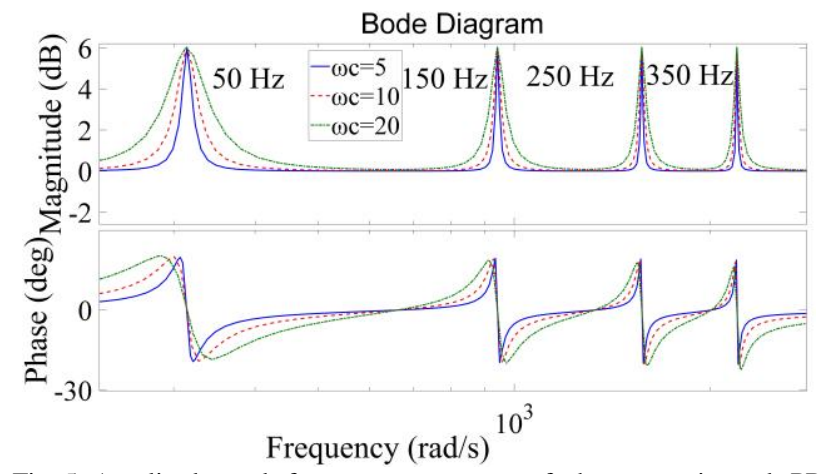

Fig. 5. Amplitude and frequency response of the approximated PR controllers with selective harmonic compensator $\left(K_{P}=1, K_{R n}=1, \omega=\right.$ $100 \pi \mathrm{rad} / \mathrm{s}, \omega_{c}=5,10$, and $\left.20 \mathrm{rad} / \mathrm{s}\right)$.

\section{DIRECT SVM FOR THE MATRIX CONVERTER}

A modulation stage is required in this scheme to control the matrix converter. The SVM is a developed modulation technique and it is adopted here. There are two ways to implement the SVM+PR controller for the matrix converter: direct and indirect method.

In the direct method, the PR controller forms a current loop and generates output voltage references based on the output current errors (reference-actual). The matrix converter input current references are specified according to the system requirements. Then the output voltage and input current references are directly used in the SVM to generate gating pulses for the semiconductor switches in the matrix converter [5].

In the direct method, the SVM is divided into virtual inversion and rectification modulation stages. In the virtual inversion modulation stage, the PR controller and SVM (for the inverter only) are used to generate gating pulses for the semiconductor switches in the virtual inverter, while the SVM (for the rectifier only) is used in the virtual rectification modulation stage to generate gating pulses for the semiconductor switches in the virtual rectifier. Then the two virtual modulation stages are combined to control the matrix converter [1]. In this work, the direct method is investigated.

Based on pulse width modulation (PWM), SVM synthesizes the desired output voltages and input currents in the form of space vectors. Switches in the matrix converter can be arranged so that any outputs can be connected to any inputs. However, the total allowed number of combinations is 27 due to the constraints of avoiding short circuits at the source side and open circuits at the inductive load side. The combinations can be classified into the following three groups.

Group I (Active States): two outputs are connected to the same input while the remaining output is connected to one of the other inputs. These 18 active vectors have fixed direction but their amplitudes vary with the instantaneous values of input voltages.

Group II (Zero States): all three outputs are connected to the same input. These 3 vectors have zero amplitude and arbitrary directions.

Group III (Rotating States): all three outputs are connected to different inputs. These 6 rotating vectors rotate with fixed amplitudes.

Assume that the known 3-phase input voltages are

$$
\begin{aligned}
& V_{A}=V_{i} \sin \left(\omega_{i} t\right) \\
& V_{B}=V_{i} \sin \left(\omega_{i} t-\frac{2 \pi}{3}\right) ; V_{C}=V_{i} \sin \left(\omega_{i} t+\frac{2 \pi}{3}\right)
\end{aligned}
$$

where $V_{\mathrm{i}}$ is the input phase voltage amplitude and $\omega_{\mathrm{i}}=$ $2 \pi f_{\mathrm{i}}$ is the input angular frequency. The output currents are

$$
\begin{aligned}
& I_{a}=I_{o} \sin \left(\omega_{o} t-\varphi_{o}\right) \\
& I_{b}=I_{o} \sin \left(\omega_{o} t-\varphi_{o}-\frac{2 \pi}{3}\right) ; I_{c}=I_{o} \sin \left(\omega_{o} t-\varphi_{o}+\frac{2 \pi}{3}\right)
\end{aligned}
$$

where $I_{\mathrm{o}}$ is the output phase current amplitude, $\omega_{\mathrm{o}}=2 \pi f_{\mathrm{o}}$ the output angular frequency and $\varphi_{\mathrm{o}}$ the phase angle.

The desired output voltages are obtained from the PR controller and the desired input currents are specified according to the system requirements. Assume they are

$$
\begin{gathered}
V_{a}=V_{o} \sin \left(\omega_{o} t\right) \\
V_{b}=V_{o} \sin \left(\omega_{o} t-\frac{2 \pi}{3}\right) ; V_{c}=V_{o} \sin \left(\omega_{o} t+\frac{2 \pi}{3}\right) \\
I_{A}=I_{i} \sin \left(\omega_{i} t-\varphi_{i}\right) \\
I_{B}=I_{i} \sin \left(\omega_{i} t-\varphi_{i}-\frac{2 \pi}{3}\right) ; I_{C}=I_{i} \sin \left(\omega_{i} t-\varphi_{i}+\frac{2 \pi}{3}\right)
\end{gathered}
$$

where $V_{\mathrm{o}}$ and $I_{\mathrm{i}}$ are the amplitudes of the expected output voltages and input currents; and $\varphi_{\mathrm{i}}$ is the input power factor angle.

In SVM, the 3-phase system variables are represented in the space vector form using

$$
x_{S}=\frac{2}{3}\left(x_{1}+a x_{2}+a^{2} x_{3}\right)
$$

where $x_{1}, x_{2}$ and $x_{3}$ are the 3-phase variables; $a=\mathrm{e}^{j(2 \pi / 3)}$ and $a^{2}=\mathrm{e}^{j(4 \pi / 3)}$; and $x_{\mathrm{S}}$ is the corresponding space vector representation after the transformation.

The 3-phase voltages and currents in (5-8) can be represented as space vectors using transformation (9). Among the 27 available states, only 21 states (18 in Group I and 3 in Group II) are used to synthesize the desired output voltages and input currents [17]. The available known active input voltage and output current vectors form hexagons as shown in Fig. 6. According to 


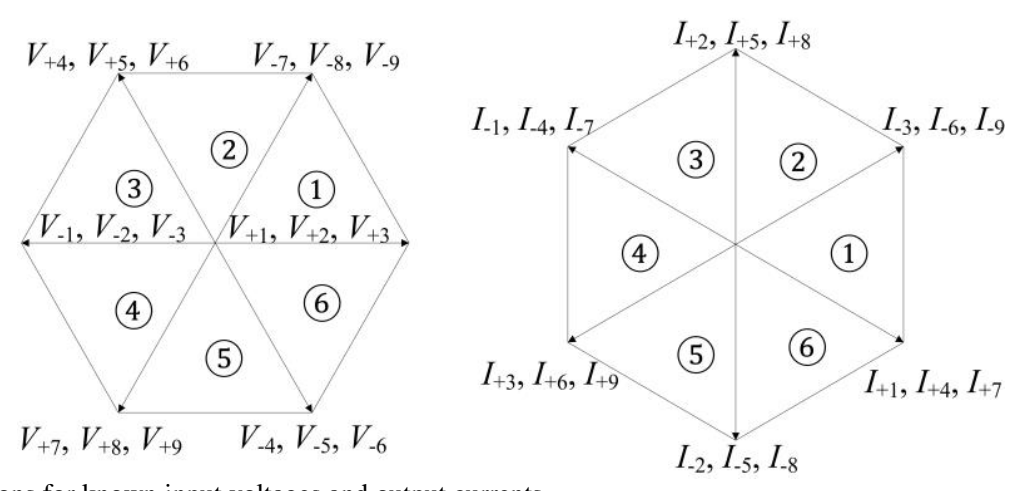

Fig. 6: Space vector hexagons for known input voltages and output currents.
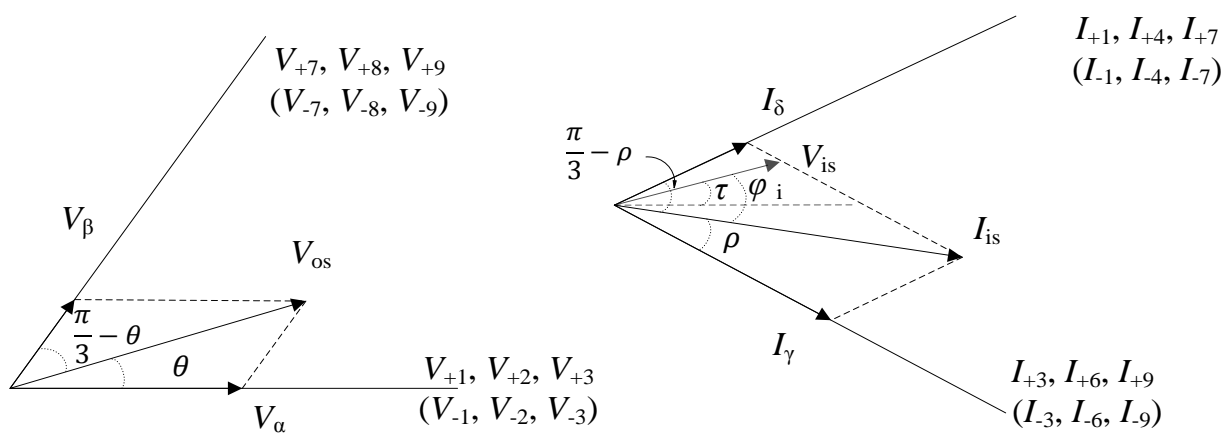

Fig. 7: Synthesis of the desired output voltage and input current vectors.

TABLE I: LOOK-UP TABLE OF THE VECTOR COMBINATIONS TO SYNTHESIZE THE OUTPUT VOLTAGE AND INPUT CURRENTS.

\begin{tabular}{|c|c|c|c|c|c|c|c|}
\hline \multicolumn{8}{|c|}{ Sector number of output voltage vector } \\
\hline \multirow{7}{*}{$\begin{array}{c}\text { Sector } \\
\text { number } \\
\text { of } \\
\text { input } \\
\text { current } \\
\text { vector }\end{array}$} & \multicolumn{2}{|r|}{1} & \multirow{2}{*}{$\begin{array}{c}\mathbf{2} \\
+4,+6,+7,+9\end{array}$} & \multirow{2}{*}{$\begin{array}{c}\mathbf{3} \\
++1,+3,+4,+6\end{array}$} & \multirow{2}{*}{$\begin{array}{c}\mathbf{4} \\
++7,+9,+1,+3\end{array}$} & \multirow{2}{*}{$\begin{array}{c}\mathbf{5} \\
++4,+6,+7,+9\end{array}$} & \multirow{2}{*}{$\begin{array}{c}\mathbf{6} \\
++1,+3,+4,+6\end{array}$} \\
\hline & 1 & $+7,+9,+1,+3$ & & & & & \\
\hline & 2 & $+8,+7,+2,+1$ & $+5,+4,+8,+7$ & $+2,+1,+5,+4$ & $+8,+7,+2,+1$ & $+5,+4,+8,+7$ & $+2,+1,+5,+4$ \\
\hline & 3 & $+9,+8,+3,+2$ & $+6,+5,+9,+8$ & $+3,+2,+6,+5$ & $+9,+8,+3,+2$ & $+6,+5,+9,+8$ & $+3,+2,+6,+5$ \\
\hline & 4 & $+7,+9,+1,+3$ & $+4,+6,+7,+9$ & $+1,+3,+4,+6$ & $+7,+9,+1,+3$ & $+4,+6,+7,+9$ & $+1,+3,+4,+6$ \\
\hline & 5 & $+8,+7,+2,+1$ & $+5,+4,+8,+7$ & $+2,+1,+5,+4$ & $+8,+7,+2,+1$ & $+5,+4,+8,+7$ & $+2,+1,+5,+4$ \\
\hline & 6 & $+9,+8,+3,+2$ & $+6,+5,+9,+8$ & $+3,+2,+6,+5$ & $+9,+8,+3,+2$ & $+6,+5,+9,+8$ & $+3,+2,+6,+5$ \\
\hline & & \begin{tabular}{l|l|l|l}
$\mathrm{t}_{\mathrm{x} 1}$ & $\mathrm{t}_{\mathrm{x} 2}$ & $\mathrm{t}_{\mathrm{y} 1}$ & $\mathrm{t}_{\mathrm{y} 2}$
\end{tabular} & $\begin{array}{lllll}\mathrm{t}_{\mathrm{x} 1} & \mathrm{t}_{\mathrm{x} 2} & \mathrm{t}_{\mathrm{y} 1} & \mathrm{t}_{\mathrm{y} 2}\end{array}$ & \begin{tabular}{l|l|l|l}
$\mathrm{t}_{\mathrm{x} 1}$ & $\mathrm{t}_{\mathrm{x} 2}$ & $\mathrm{t}_{\mathrm{y} 1}$ & $\mathrm{t}_{\mathrm{y}}$
\end{tabular} & \begin{tabular}{l|l|l|l|}
$\mathrm{t}_{\mathrm{x} 1}$ & $\mathrm{t}_{\mathrm{x} 2}$ & $\mathrm{t}_{\mathrm{y} 1}$ & $\mathrm{t}_{\mathrm{y}}$
\end{tabular} & \begin{tabular}{l|l|l|l}
$\mathrm{t}_{\mathrm{x} 1}$ & $\mathrm{t}_{\mathrm{x} 2}$ & $\mathrm{t}_{\mathrm{y} 1}$ & $\mathrm{t}_{\mathrm{y} 2}$ \\
\end{tabular} & \begin{tabular}{l|l|l|l|l}
$\mathrm{t}_{\mathrm{x} 1}$ & $\mathrm{t}_{\mathrm{x} 2}$ & $\mathrm{t}_{\mathrm{y} 1}$ & $\mathrm{t}_{\mathrm{y}}$
\end{tabular} \\
\hline
\end{tabular}

the locations of the desired vectors, appropriate known vectors can be used to produce the desired vectors

In SVM the nearest adjacent vectors to the current sector are used to form the required vectors while the application of non-adjacent vectors may generate higher total harmonic distortion (THD) and switching losses [18]. The chosen vectors must accomplish the syntheses of both the output voltages and input currents at the same time and they are summarized in Table I. In order to understand the algorithm without losing generality, it is assumed that, at a given instant in time, the desired output voltage and input current vectors both lie in their corresponding sector (1), as shown in Fig. 6.

The required output voltage and input current vectors can be decomposed into $V_{\alpha}$ and $V_{\beta}$, and $I_{\gamma}$ and $I_{\delta}$, respectively, as shown in Fig. 7. Once the vector combinations are determined (Table I) the corresponding duty cycles can be calculated. According to Figs. 6 and 7, and Table I, the duty cycles are given by

$$
\begin{gathered}
t_{x 1}=(-1)^{m+n} \frac{2}{\sqrt{3}} T_{P} q \frac{\sin (\theta) \sin (\rho)}{\cos \left(\varphi_{i}\right)} \\
t_{x 2}=(-1)^{m+n+1} \frac{2}{\sqrt{3}} T_{P} q \frac{\sin (\theta) \sin (\pi / 3-\rho)}{\cos \left(\varphi_{i}\right)} \\
t_{y 1}=(-1)^{m+n+1} \frac{2}{\sqrt{3}} T_{P} q \frac{\sin (\pi / 3-\theta) \sin (\rho)}{\cos \left(\varphi_{i}\right)} \\
t_{y 2}=(-1)^{m+n} \frac{2}{\sqrt{3}} T_{P} q \frac{\sin (\pi / 3-\theta) \sin (\pi / 3-\rho)}{\cos \left(\varphi_{i}\right)} \\
t_{0}=T_{P}-\left(\left|t_{x 1}\right|+\left|t_{x 2}\right|+\left|t_{y 1}\right|+\left|t_{y 2}\right|\right) \\
q=\frac{V_{o}}{V_{i}} \leq \mid \frac{2 \sin (\theta+\pi / 3) \sin (\rho+\pi / 3)}{\sqrt{3} \cos \left(\varphi_{i}\right)}
\end{gathered}
$$


where $0 \leq \theta \leq \pi / 3$ is the angle between the desired output space vector $V_{\text {os }}$ and the right-hand adjacent vector $V_{\alpha} ; 0 \leq$ $\rho \leq \pi / 3$ is the angle between the desired input space vector $I_{\mathrm{is}}$ and the right-hand adjacent vector $I_{\gamma} ; T_{\mathrm{p}}$ is the cycle period; $t_{\mathrm{x} 1}, t_{\mathrm{x} 2}$ and $t_{\mathrm{y} 1}, t_{\mathrm{y} 2}$ are the working times corresponding to the chosen vectors; and $m$ and $n$ denote the $m^{\text {th }}$ output voltage vector sector and the $n^{\text {th }}$ input current vector sector $(m, n=1,2,3,4,5,6)$. If any of the working times are negative, the negative counterpart vector should be chosen instead of the assumed positive vector tabulated in Table I. Note that an appropriate commutation technique is essential in the hardware and it helps improve the power quality.

\section{OVERALl CONTROLLER}

According to the above description of the PR controller and SVM, the overall PR controller with harmonic compensators based on the matrix converter SVM is obtained, as shown in Fig. 8. The controller structure is as simple as the PI controller. Output currents and input voltages are obtained using sensors. A phase locked loop (PLL) is used to determine the input voltage angles thus the a vector sectors. The controller is implemented in the natural $a b c$ frame and no frame transformations are required in this controller.

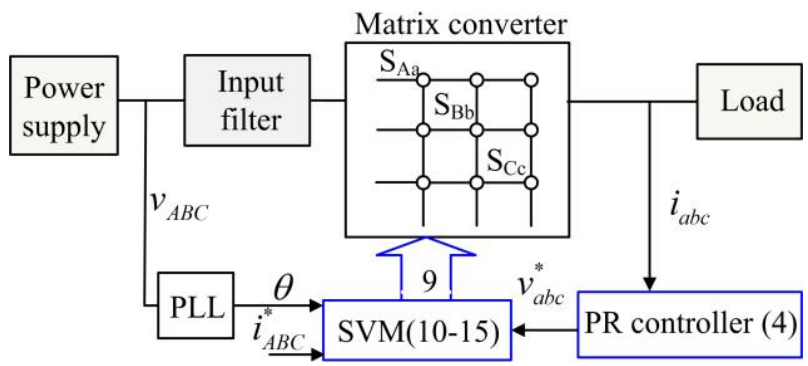

Fig. 8. PR controller based on the matrix converter SVM.

TABLE. II

SIMULATION SYSTEM PARAMETERS

\begin{tabular}{|c|c|c|c|c|c|c|}
\hline $\boldsymbol{V}_{\boldsymbol{i}}[\mathbf{V}]$ & $\boldsymbol{f}_{\boldsymbol{i}}[\mathbf{H z}]$ & $\boldsymbol{L}_{\boldsymbol{A}}[\mathbf{m H}]$ & $\boldsymbol{r}_{\boldsymbol{A}}[\mathbf{\Omega}]$ & $\boldsymbol{C}_{\boldsymbol{A} \boldsymbol{B}}[\boldsymbol{\mu \mathbf { F }}]$ & $\mathbf{L}[\mathbf{m H}]$ & $\boldsymbol{R}[\mathbf{\Omega}]$ \\
\hline 100 & 50 & 4.8 & 0.5 & 6 & 20 & 10 \\
\hline
\end{tabular}

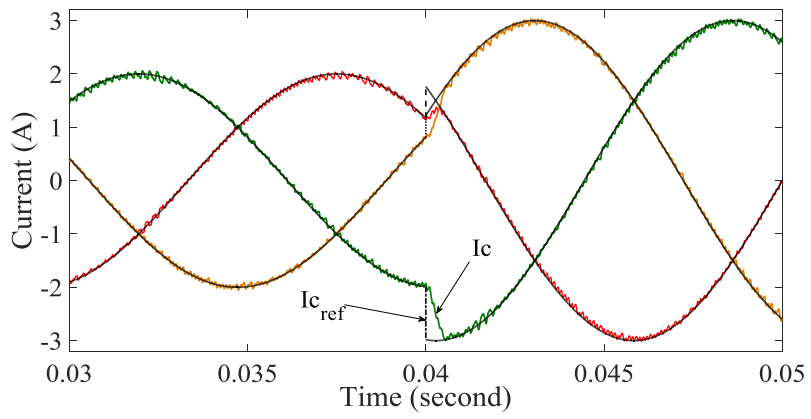

Fig. 9. Dynamic response of the PR controller to a step reference $\left(K_{P}=\right.$ $\left.350, K_{R I}=600, K_{R 3}=K_{R 5}=K_{R 7}=200, \omega=120 \pi \mathrm{rad} / \mathrm{s}, \omega_{c}=2 \pi \mathrm{rad} / \mathrm{s}\right)$.

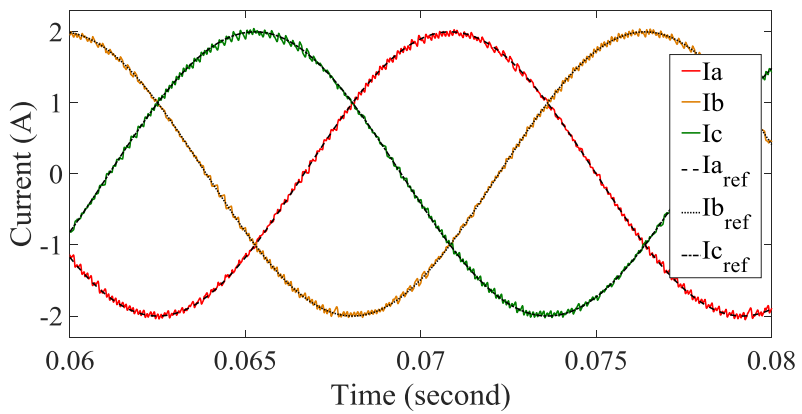

(a)

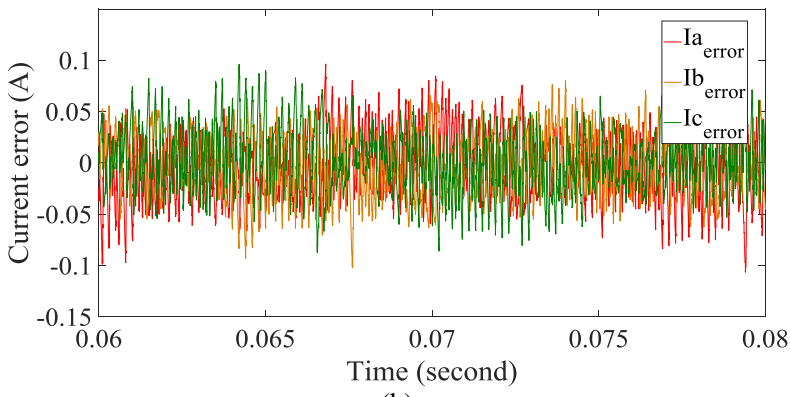

(b)

Fig. 10. Steady-state error performance of the PR controller $\left(K_{P}=350\right.$, $K_{R 1}=600, K_{R 3}=K_{R 5}=K_{R 7}=200, \omega=120 \pi \mathrm{rad} / \mathrm{s}, \omega_{c}=2 \pi \mathrm{rad} / \mathrm{s}$ ): (a) three-phase currents and (b) three-phase current errors

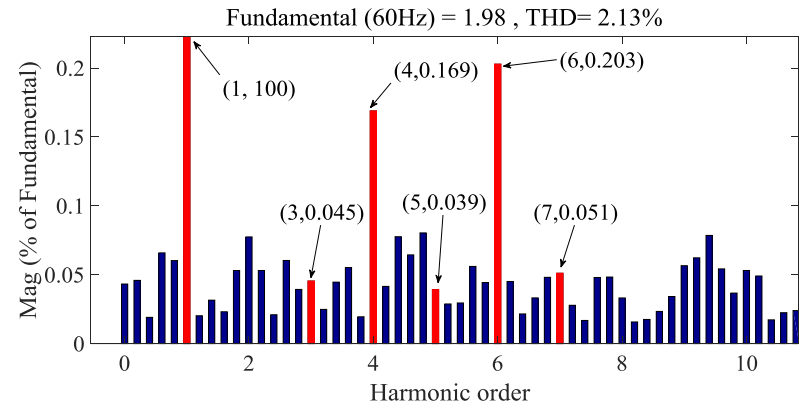

Fig. 11. THD analysis of PR controlled matrix converter output current (without harmonics compensator, $K_{P}=350, K_{R I}=600, K_{R n}=0, \omega=$ $120 \pi \mathrm{rad} / \mathrm{s}, \omega_{c}=2 \pi \mathrm{rad} / \mathrm{s}$ ).

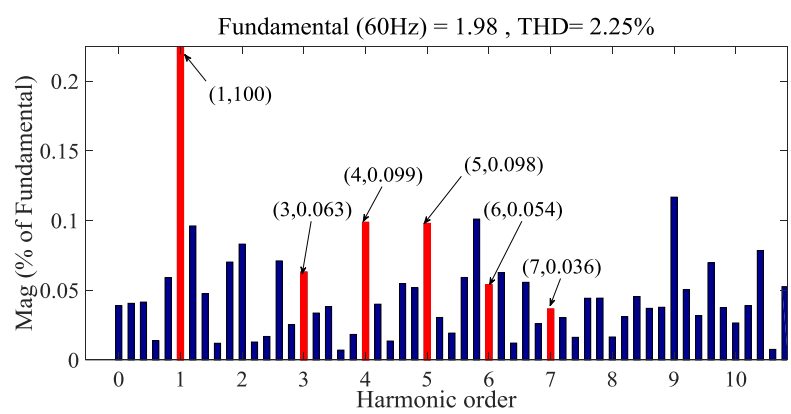

Fig. 12. THD analysis of PR controlled matrix converter output current (with harmonics compensator, $K_{P}=350, K_{R I}=600, K_{R 4}=K_{R 6}=500, K_{R 7}$ $\left.=300, \omega=120 \pi \mathrm{rad} / \mathrm{s}, \omega_{c}=2 \pi \mathrm{rad} / \mathrm{s}\right)$.

\section{Simulation Results}

This section presents the simulation results and the approximated PR controllers are examined here. The simulation parameters are tabulated in Table II. The simulation results are presented in Figs. 9 to 12. In Fig. 9, the dynamic response of the controller to a step change of the reference signal is evaluated. The controller 
parameters used in this case are: $K_{P}=350, K_{R 1}=600, K_{R}$ $=K_{R 5}=K_{R 7}=200, \omega=120 \pi \mathrm{rad} / \mathrm{s}, \omega_{c}=2 \pi \mathrm{rad} / \mathrm{s}$. The three-phase matrix converter output current references are

$[2 \sin (120 \pi \mathrm{t}) 2 \sin (120 \pi \mathrm{t}-2 \pi / 3) 2 \sin (120 \pi \mathrm{t}+2 \pi / 3)] \mathrm{A}$

before $0.04 \mathrm{~s}$ and

$[3 \sin (120 \pi \mathrm{t}) 3 \sin (120 \pi \mathrm{t}-2 \pi / 3) 3 \sin (120 \pi \mathrm{t}+2 \pi / 3)] \mathrm{A}$

after this time. From Fig. 9, we can see the controller exhibits a good dynamic response and tracks the prescribed reference effectively.

Fig. 10 shows the steady-state error performance of the PR controller and harmonic compensator. The same controller parameters stated above are used in this case. As can be seen the steady-state errors are negligible.

Figs. 11 and 12 demonstrate the performance of the selective harmonic compensator. Fig. 11 shows the fast Fourier transform (FFT) analysis and it seems the $4^{\text {th }}$ and $6^{\text {th }}$ harmonics are relatively significant compared to others Here, harmonic orders of $4^{\text {th }}, 6^{\text {th }}$ and $7^{\text {th }}$ are considered in the selective harmonic compensator and results are shown in Fig. 12. The controller parameters used in this case are: $K_{P}=350, K_{R 1}=600, K_{R 4}=K_{R 6}=500, K_{R 7}=300, \omega=$ $120 \pi \mathrm{rad} / \mathrm{s}, \omega_{c}=2 \pi \mathrm{rad} / \mathrm{s}$. It is evident that specific harmonics $\left(4^{\text {th }}, 6^{\text {th }}\right.$ and $\left.7^{\text {th }}\right)$ are suppressed appreciably and the controller is effective.

It is worth noting that the harmonic compensator does not necessarily improve the overall THD performance. In fact, it affects the harmonic spectrum as it causes a gain reduction to the frequencies near the resonant frequencies when it compensates the targeted harmonics as shown in Fig. 5. The THD performance of the matrix converter output currents is also influenced by the voltage transfer ratio $q$ in (15). With the proposed scheme, the input power factor can also be regulated (being able to reach a unity power factor).

\section{CONCLUSIONS}

The PR controller and selective harmonics compensator are implemented based on matrix converter SVM. PR controllers have good performance in tracking sinusoidal variables. The steady state errors can be removed in comparison to the PI controller. The complex frame transformations are avoided since the controller can be implemented in the natural frame. As a result, the computation burden is alleviated. The PR controller has fast dynamic performance and the harmonic compensator can compensate the targeted harmonics effectively. The simulation results presented validate the effectiveness of the proposed PR controller for matrix converter.

\section{REFERENCES}

[1] J. Zhang, L. Li, and D. G. Dorrell, "DQ Coupling Suppressed PID Controller for the Transmission Line Power Flow Control Using a Matrix Converter," IEEE Ind. Electron. Soc. Annu. Meeting (IECON16), Florence, Italy, pp. $6249-6254$, October 2016.

[2] P. W. Wheeler, J. Rodriguez, J. C. Clare, L. Empringham and A. Weinstein, "Matrix converters: a technology review," IEEE Trans. Ind. Electron., vol. 49, no. 2, pp. 276-288, 2002.
[3] J. Monteiro, J. F. Silva, S. F. Pinto, and J. Palma, "Linear and sliding-mode control design for matrix converter-based unified power flow controllers," IEEE Trans. Power Electron., vol. 29, no. 7, pp. 3357-3367, 2014.

[4] S. Pinto and J. Silva, "Sliding mode direct control of matrix converters," IET Electric Power Applications, vol. 1, no. 3, pp. 439-448, 2007.

[5] J. Zhang, D. G. Dorrell, and L. Li, "Applications of the Direct Space Vector Modulation Controlled Matrix Converter as the Unified Power Flow Controller," 8th Int. conf. power electron. motor drives, Glasgow, UK, , pp. 6, April 2016.

[6] J. Rocabert, A. Luna, F. Blaabjerg, and P. Rodriguez, "Control of power converters in AC microgrids," IEEE Trans. Ind. Electron., vol. 27, no. 11, pp. 4734-4749, 2012.

[7] Y. Han, P. Shen, and J. M. Guerrero, "Stationary frame current control evaluations for three-phase grid-connected inverters with PVR-based active damped LCL filters," $J$. Power Electron., vol. 16, no. 1, pp. 297-309, 2016.

[8] R. Teodorescu, F. Blaabjerg, M. Liserre, and P. C. Loh, "Proportional-resonant controllers and filters for gridconnected voltage-source converters," IEE Proc. Electric Power Applicat., vol. 153, no. 5, pp. 750-762, 2006.

[9] H. Cha, T. K. Vu, and J. E. Kim, "Design and control of Proportional-Resonant controller based Photovoltaic power conditioning system," Energy Conversion Congr. Exposition (ECCE), IEEE, pp. 2198-2205, 2009.

[10] A. Timbus, M. Liserre, R. Teodorescu, P. Rodriguez, and F. Blaabjerg, "Evaluation of current controllers for distributed power generation systems," IEEE Trans. Power Electron., vol. 24, no. 3, pp. 654-664, 2009.

[11] A. V. Timbus, M. Ciobotaru, R. Teodorescu, and F. Blaabjerg, "Adaptive resonant controller for grid-connected converters in distributed power generation system," $21^{\text {st }}$ IEEE Applied Power Electron. Conf. and Exposition (APEC'06), pp. 6, 2006.

[12] A. Hasanzadeh, O. C. Onar, H. Mokhtari, and A. Khaligh, "A proportional-resonant controller-based wireless control strategy with a reduced number of sensors for paralleloperated UPSs," IEEE Trans. Power Del., vol. 25, no. 1, pp. 468-478, 2010.

[13] F. Blaabjerg, R. Teodorescu, M. Liserre, and A. V. Timbus, "Overview of control and grid synchronization for distributed power generation systems," IEEE Trans. Ind. Electron., vol. 53, no. 5, pp. 1398-1409, 2006.

[14] A. Vidal, F. D. Freijedo, A. G. Yepes, P. FernandezComesana, J. Malvar, Ó. López, and J. Doval-Gandoy, "Assessment and optimization of the transient response of proportional-resonant current controllers for distributed power generation systems," IEEE Trans. Ind. Electron., vol. 60, no. 4, pp. 1367-1383, 2013.

[15] G. Shen, X. Zhu, J. Zhang, and D. Xu, "A new feedback method for PR current control of LCL-filter-based gridconnected inverter," IEEE Trans. Ind. Electron., vol. 57, no. 6, pp. 2033-2041, 2010.

[16] R. Teodorescu, F. Blaabjerg, and M. Liserre, "Proportionalresonant controllers. A new breed of controllers suitable for grid-connected voltage-source converters," OPTIM, Brasov, Romania. 2004.

[17] J. W. Kolar, T. Friedli, J. Rodriguez, and P. W. Wheeler, "Review of three-phase PWM AC-AC converter topologies," IEEE Trans. Ind. Electron., vol. 58, no. 11, pp. 4988-5006, 2011.

[18] V. H. Prasad, "Analysis and Comparison of Space Vector Modulation schemes for Three-Leg and Four-Leg Voltage Source inverters, " Master Thesis, Virginia Polytechnic Institute and State University, US, May 1997. 